\title{
1 Analysis of the Dimensions of Physiotherapy Index 2 of Ventilatory Workload in People with Chronic 3 Obstructive Pulmonary Disease During Stability and 4 Exacerbation in An Outpatient Setting
}

5 Rodrigo Muñoz Cofré ${ }^{1,2}$, Mariano del Sol ${ }^{1}$, Paul Medina González ${ }^{3}$, Jorge Valenzuela Vásquez

$6{ }^{4}$, Gerardo Molina Vergara ${ }^{5}$, Ramón Pinochet Urzúa ${ }^{6}$, Pablo A. Lizana ${ }^{7}$ and Máximo Escobar 7 Cabello ${ }^{2,3}$.

81 Programa de Doctorado en Ciencias Morfológicas, Universidad de La Frontera, Temuco, Chile. Avenida 9 Francisco Salazar \#01145; Telephone: +56452596550.

102 Laboratorio de Función-Disfunción Ventilatoria Universidad Católica del Maule, Talca, Chile. Avenida San 11 Miguel \#3605; Telephone: +56712203100.

123 Departamento de Kinesiología Universidad Católica del Maule, Talca, Chile. Avenida San Miguel \#3605;

13 Telephone: +56712201119 .

144 Hospital El Carmen-Dr. Luis Valentín Ferrada, Maipú, Santiago de Chile. Camino a Rinconada \#1201;

15 Telephone: +562226120491.

165 Departamento de Educación de la Ilustre Municipalidad de Quirihue, Quirihue, Chile. Avenida

17 Independencia \#699; Telephone: +56422531214.

6 Hospital Padre Alberto Hurtado, San Ramón, Santiago de Chile. Avenida Esperanza \#2150; Telephone: +569225760600 .

7 Laboratory of Morphological Sciences, Instituto de Biología, Pontificia Universidad Católica de Valparaíso, Valparaíso, Chile. Avenida Universidad \#330, Curauma; Telephone: +56322274841.

Contact: Rodrigo Muñoz Cofré, Mobile phone: +56978970129, E-mail: rodrigomunozcofre@gmail.com. Address: Avenida Francisco Salazar \# 01145, Universidad de La Frontera, Temuco, Chile.

Abstract: Background and objective: Addressing the global morbidity associated with pulmonary disease is an important need for the respiratory community. However, there is also a growing momentum to show the efficacy of new tools of diagnosis. Despite this, there are few physiotherapeutic tools that help identify and categorize these conditions. The aim was to analyze the variables of physiotherapy index of the ventilatory workload (PIVW) in people with chronic obstructive pulmonary disease (COPD) during stability and exacerbation in an outpatient setting. Material and Methods: Analyzed retrospectively of 198 clinical records were reviewed. The PIVW was extracted in stability and exacerbation of these patients with COPD. After applying the exclusion and inclusion criteria; 54 patients were classified. Through the statistical analysis of chisquare, a significant association was reported for each of the variables and the total PIVW score. Results: when analyzing the baseline with the peak of PIVW, there was a significant increase in patients COPD exacerbation. Similarly, the variables that constitute the loads, translations and supports underwent a significant increase from baseline to exacerbation $(\mathrm{p}<0.0001)$, except for the additional oxygen contribution, where the frequency of patients was the same in basal and exacerbation as well. Conclusions: the PIVW, serves to determine ventilatory problemas in outpatients, characterizing the specific changes of loads, translators or assistance.

Keywords: ventilatory assessment; physiotherapy; chronic obstructive pulmonary disease

Physical Therapy represents a field of professional action aimed at solving health problems linked to the dysfunctions of human movement. Traditionally these complications were resolved by consulting a Kinesiology Vademecum, however, this represents a basic complement to the therapy [1]. This is in contrast to the specificity of the evaluation of respiratory problems, which is widely 
used in daily clinical practice. This is assigned a score in order to grade its severity and also to guide decisions and interventions.

In this context and for the purpose of having a correlation between evaluation and therapeutic action as well as to objectify the different profiles of ventilatory dysfunction, the Physiotherapeutic Index of the Impairment of Ventilatory Work (PIVW) was proposed as a clinical assessment tool to analyze the ventilatory balance - imbalance and to standardize the evaluation of the respiratory system by the physiotherapist [2,3]. The PIVW is a clinical instrument that has high inter-evaluative reliability ( $\mathrm{p}=0.9, \mathrm{~K}=0.84$ ). It is made up of 8 variables, which in their all-round clinimetric capacity have proved to be a good differentiator of critical functional contexts, particularly those related to the respiratory problems in hospitalized patients $[4,5,6]$, including the patients of nocturnal physiotherapy clinics [7] and those with external ventilatory assistance [3].

During the natural course of COPD, the exacerbations are frequent. They are characterized by dyspnoea, coughing, the production of sputum and the persistent limitation of air flow both will cause deterioration of lung ventilation [8], which will have a direct impact on the affected patient's quality of life [9]. In addition, COPD have a high prevalence worldwide and in Chile. In light of the mortality increasement due to respiratory diseases recorded in 1999, the Adult Respiratory Diseases (ARD) program began in Chile in 2001. This includes a monitoring plan, the main objective of which is to reduce morbidity and mortality from these causes [10]. The aim of this study was to analyze the variables of PIVW in people with COPD during stability and exacerbation in an outpatient setting.

\section{MATERIALS AND METHODS}

Study design: was retrospective descriptive. One hundred and ninety-eight patients in control in the ARD room of the Hospital Padre Alberto Hurtado, Santiago, Chile. In stability and exacerbation was compared PIVW. They will be included the patients with: i) medical diagnosis of COPD [8], ii) updated medical control iii) standard inhalation treatment (long-acting beta-agonist, short-acting anticholinergic and short-acting beta-agonist), iv) stable history in the last six months' prior of last exacerbation (Figure 1). This project was approved by the Committee of scientific ethics of the 'Maule Catholic University' (resolution 23/2016) and by the Coordinator of Physical Therapy at the Padre Alberto Hurtado Hospital. 
75

Table 1. Adult PIVW, divided by variables and their scores.

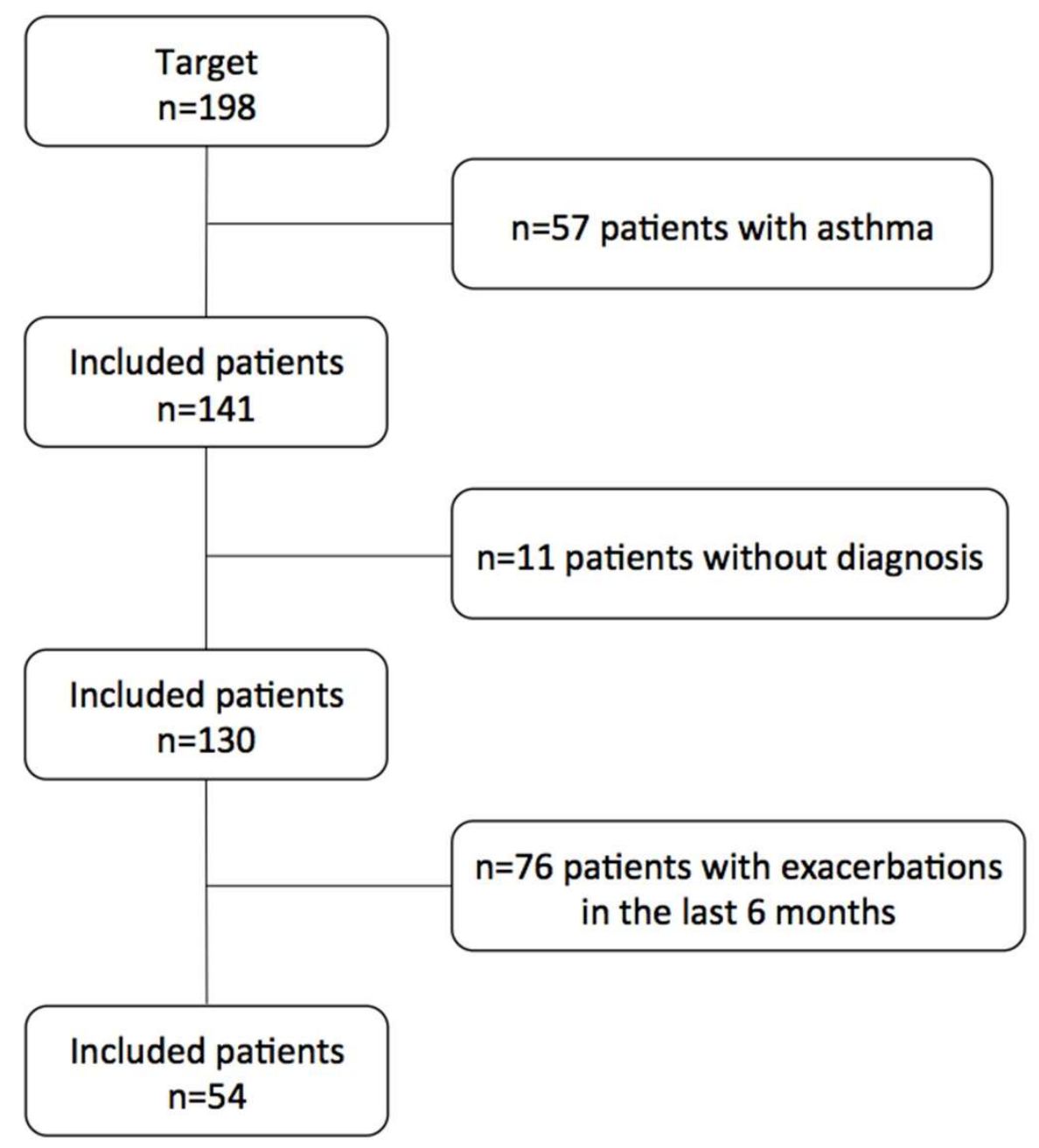

Figure 1. Study flowchart.

Classification and Categorization of the PIVW: The PIVW is a clinical instrument consisting of eight variables, each of which has a score ranging from zero to three points according to clinical commitment (Table 1). These are classified as:

\begin{tabular}{|c|c|c|c|c|c|c|c|c|}
\hline $\mathbf{R R}$ & $\mathrm{O}_{2}(\%)$ & $\mathrm{SO}_{2}(\%)$ & UAM & PM & AR & Cough & APA & SCORE \\
\hline $10-16$ & $100-98$ & 21 & Without UAM & 0 & Without AR & $\begin{array}{c}\text { Spontaneous or effective } \\
\text { cough }\end{array}$ & No required & 0 \\
\hline $17-25$ & $97-95$ & $22-28$ & $\begin{array}{l}\text { Diaphragmati } \\
\text { c overload }\end{array}$ & $1-7$ & $\begin{array}{l}\text { Prolonged } \\
\text { expiration }\end{array}$ & $\begin{array}{c}\text { Threshold disorder or } \\
\text { inspiratory reserve } \\
\text { volume }\end{array}$ & 2 attempts & 1 \\
\hline $26-34$ & $94-92$ & $29-49$ & AMR I or E & $8-14$ & $\begin{array}{l}\text { Wheezing or } \\
\text { expiratory } \\
\text { rhonchi }\end{array}$ & $\begin{array}{c}\text { Compressive or } \\
\text { expulsive phase altered }\end{array}$ & 3-4 attempts & 2 \\
\hline $35+$ & $<91$ & $>50$ & $\begin{array}{c}\text { AMR I and E/ } \\
\text { PR }\end{array}$ & $15-20$ & $\begin{array}{l}\text { Wheezing or } \\
\text { expiratory and }\end{array}$ & $\begin{array}{l}\text { Absent or severely } \\
\text { altered mechanism }\end{array}$ & $\begin{array}{c}\quad>5 \\
\text { attempts }\end{array}$ & 3 \\
\hline
\end{tabular}


inspiratory

rhonchi

RR: respiratory rate; $\mathbf{O}_{2}$ : additional oxygen contribution; $\mathrm{SO}_{2}$ : oxygen saturation; UAM: use of accessory muscles; PM: pulmonary murmur; AR: airway resistance; APA: attempts to permeabilize the airway; AMR: accessory muscle recruitment; I: inspiratory; E: expiratory; PR: paradoxical respiration. Modified from Escobar et al. (2000).

-Loads; internal or external biophysical phenomena that increase the mechanical or physiological expenditures of the ventilatory system.

-Translations; set of variables that allow adequate monitoring of the tendencies towards imbalance in the system.

-Supports; internal or external biophysical adjustments that stabilize the equilibrium costs of the ventilatory system in a given moment [2]. Detail of the measured variables (Table 2).

-Respiratory Rate (RR): the number of breaths per minute was measured with a Casio chronometer (model Hs-3v-1b).

-Additional oxygen contribution (O2): the additional oxygen support administered, was measured as a percentage, independent from the system used (high or low flow).

-Oxygen Saturation (SO2): was recorded with an oximeter with a NONIN pulse (ONYX 9500), attached to the index finger of each patient.

-Use of Accessory Muscles (UAM): accessory muscle activity was measured by observation and/or contact in a sitting position and with minimum intervention, in order to gauge the level more clearly.

-Pulmonary murmur (PM): was measured with a stethoscope $\left(3 \mathrm{M}^{\mathrm{TM}}\right.$ Littmann ${ }^{\circledR}$ Classic III, New Jersey, USA) At total lung capacity, the central point of each of the ten quadrants described below was estimated.: at the front at the two apexes, at the two bases at the side, while at the back they were taken from two higher points, two middle points and two lower points. Each location was awarded points in the following manner:

0 points, restrained pulmonary murmur, 1 point, diminished pulmonary murmur and 2 points suppressed pulmonary murmur. The sum of the ten locations was categorized according to table 1 .

-Airway resistance (AR): Once the inspiratory and expiratory phase was delimited, the presence or absence of prolonged expiration, expiratory wheezing or biphasic wheezing was auscultated with a stethoscope ( $3 \mathrm{M}^{\mathrm{TM}}$ Littmann ${ }^{\circledR}$ Classic III, New Jersey, USA). And the data were scored according to table 1.

-Cough: Its evaluation was clinical, it was determined by the kinematic observation of a voluntary coughing effort: i) normal presence of the three phases, ii) upset to trigger or preparation stage (volume of inspiratory reserve), alteration of the compressive-expulsive phase and absent mechanism [11].

-Attempts to Permeabilize the airway (APA): the necessary number of times for the repetition of the procedure was established so that the physiotherapist could check if the airway was cleared. The sum of the eight variables results in a total PIVW score which is categorized as mild, moderate or severe ventilatory compromise [3] (Table 2).

Table 2. Classification and categorization of PIVW.

\begin{tabular}{|c|c|c|c|c|c|}
\hline \multirow[t]{3}{*}{ Classification: } & Loads & $\mathrm{AR}, \mathrm{PM}$ & Categorization & Mild & $1-7$ \\
\hline & Translation & $\mathrm{RR}, \mathrm{SO}_{2}, \mathrm{UAM}, \mathrm{APA}$ & & Moderat & $8-15$ \\
\hline & $\begin{array}{l}\text { S } \\
\text { Sunnorts }\end{array}$ & $\mathrm{O}_{2}$ Cough & $\begin{array}{l}\text { ventilatory } \\
\text { imnairment }\end{array}$ & $\begin{array}{l}\text { e } \\
\text { Severe }\end{array}$ & $16-24$ \\
\hline
\end{tabular}

RR: respiratory rate; $\mathbf{O}_{2}$ : additional oxygen contribution; $\mathrm{SO}_{2}$ : oxygen saturation; $\mathbf{U A M}$ : use of accessory muscles; PM: pulmonary murmur; AR: airway resistance; APA: attempts to permeabilize the airway. Modified from Escobar et al. (2000). 
Procedures: Data was collected from the clinical records, between the months of March and September 2017. From the clinical records, the following information was obtained:

i) post-bronchodilator spirometry and medical diagnosis, ii) base PIVW, recording the median of the weekly evaluations during six months of stability iii) PIVW in exacerbation. To guarantee the validity of these results, only the records from the incumbent physiotherapist (RMC), a specialist in cardiopulmonary rehabilitation, were transcribed.

Statistical analysis: To analyze the results, Microsoft Office Excel (version 2010®, Washington, United States) was used to tabulate the data and Graph Pad Prism (version 5.0®, San Diego, United States) and STATA 13.0 were used for the statistical analysis. The data was presented with median and interquartile ranges and/or average $+/$ - standard deviation. A symmetry test was performed to compare each of the eight variables and the total PIVW score during baseline and exacerbation. To determine significant differences in the total PIVW score according to the data distribution, a Student's test or Mann-Whitney U test was used, respectively. Finally, a level of significance of $\mathrm{p}<$ 0.05 was considered.

\section{RESULTS}

For the clinical records, 198 patients were included, 57 patients were excluded for having a diagnosis of asthma, 11 for not having a clear diagnosis and 76 for having presented one or more exacerbations in the six months prior to the cut-off date (Figure 1). Of the 54 resulting patients, 31 females and 23 males. The severity of the picture was advanced (Table 3).

Table 3. Characterization of the study group in baseline.

\begin{tabular}{lcc}
\hline VARIABLE & Female & Male \\
Number (percentage) & $31(57,40)$ & $23(42,60)$ \\
Age (years) & $63.20 \pm 8.67$ & $66.16 \pm 7.10$ \\
Weight (kilograms) & $68.68 \pm 21.58$ & $65.12 \pm 10.13$ \\
Height (centimeters) & $152.37 \pm 6.95$ & $163.08 \pm 4.10$ \\
FVC (\% of prediction) & $69.58 \pm 11.44$ & $58.17 \pm 10.64$ \\
FEV $_{1}(\%$ of prediction) & $46.46 \pm 7.59$ & $35.12 \pm 9.56$ \\
FEV $_{1} /$ FVC $(\%)$ & $41 \pm 2,6$ & $31 \pm 0,4$ \\
\hline
\end{tabular}

FVC: forced vital capacity; FEV1: forced expiratory volume in 1 second. The measurements for the female and male are reported as mean \pm standard deviation. Post-bronchodilator spirometry.

In the RR there was an increase of $31.48 \%$ and $25.93 \%$ in scores 2 and 3, respectively. In the variable $\mathrm{O} 2$ no significant changes were observed. $\mathrm{SO} 2$ increased by $29.63 \%$ in the score 3 . The UAM in the score 2 increased by $81.48 \%$. The MP increased $72.22 \%$ in the score 2 . The RA increased $20.37 \%$ and $38.89 \%$ in the 2 and 3 points, respectively. In Cough, score 1 increased by $79.93 \%$ during the exacerbation. APA increased by $83.33 \%$ in score 3 . Finally, patients with a severe commitment increased by $33.33 \%$ (Table 4 ). When comparing the baseline state and the peak, there was a significant increase on the PIVW of 9 to 15 points (Figure 2).

Table 4. Statistical significance of the loads, translations and supports.

\begin{tabular}{|c|c|c|c|c|c|}
\hline & \multicolumn{2}{|c|}{ BASELINE } & \multicolumn{2}{|c|}{ EXACERBATION } & \multirow[b]{2}{*}{ Valeu p } \\
\hline & $\mathbf{F}$ & $\%$ & $\mathbf{F}$ & $\%$ & \\
\hline \multicolumn{6}{|l|}{ RR } \\
\hline 0 & 4 & 7.41 & 0 & 0 & \\
\hline
\end{tabular}




$\begin{array}{cccccc}1 & 35 & 64.81 & 8 & 14.81 & \\ 2 & 14 & 25.93 & 31 & 57.41 & 0.0001 \\ 3 & 1 & 1.85 & 15 & 27.78 & \\ \mathrm{O}_{2} & & & & & \\ 0 & 41 & 75.93 & 41 & 75.93 & 1 \\ 1 & 13 & 24.07 & 13 & 24.07 & \\ 2 & 0 & 0 & 0 & 0 & \\ 3 & 0 & 0 & 0 & 0 & \\ \mathrm{SO}_{2} & & & & & \\ 0 & 2 & 3.70 & 1 & 1.85 & \\ 1 & 20 & 37.04 & 2 & 3.70 & \\ 2 & 24 & 44.44 & 27 & 50.00 & \\ 3 & 8 & 14.81 & 24 & 44.44 & \end{array}$

UAM

$\begin{array}{cc}0 & 1 \\ 1 & 44 \\ 2 & 9 \\ 3 & 0\end{array}$

1.85

0

0

81.48

1.85

16.67

98.15

0.0001

PM

0

0

0

0

$\begin{array}{lll}1 & 41 & 77.78\end{array}$

0

0

0

0

$2 \quad 12$

22.22

94.44

0.0001

3

0

0

5.56

AR

0

1.85

0

$\begin{array}{ll}1 & 32\end{array}$

59.26

1.85

21

38.89

59.26

0.0001

3

0

38.89

Cough

$\begin{array}{cc}0 & 48 \\ 1 & 6 \\ 2 & 0 \\ 3 & 0\end{array}$

88.89
11.11
0
0

21

$\begin{array}{cccccc}0 & 44 & 81.48 & 6 & 11.11 & \\ 1 & 5 & 9.26 & 0 & 0 & \\ 2 & 5 & 9.26 & 3 & 5.56 & 0.0001 \\ 3 & 0 & 0 & 45 & 83.33 & \\ \text { PIVW } & & & & & \\ \text { Mild } & 17 & 31.48 & 0 & 0 & 0.0001 \\ \text { oderate } & 37 & 68.52 & 36 & 66.67 & \end{array}$

0
47
7
0

0

87.04

12.96

0.0001

APA 
F: frequency; \%: percentage; RR: respiratory rate; $\mathrm{O}_{2}$ : additional oxygen contribution; $\mathrm{SO}_{2}$ : oxygen saturation; UAM: use of accessory muscles; PM: pulmonary murmur; AR: airway resistance; APA: attempts to permeabilize the airway; PIVW: physiotherapy index of the ventilatory workload. Prueba estadística chi-cuadrado.

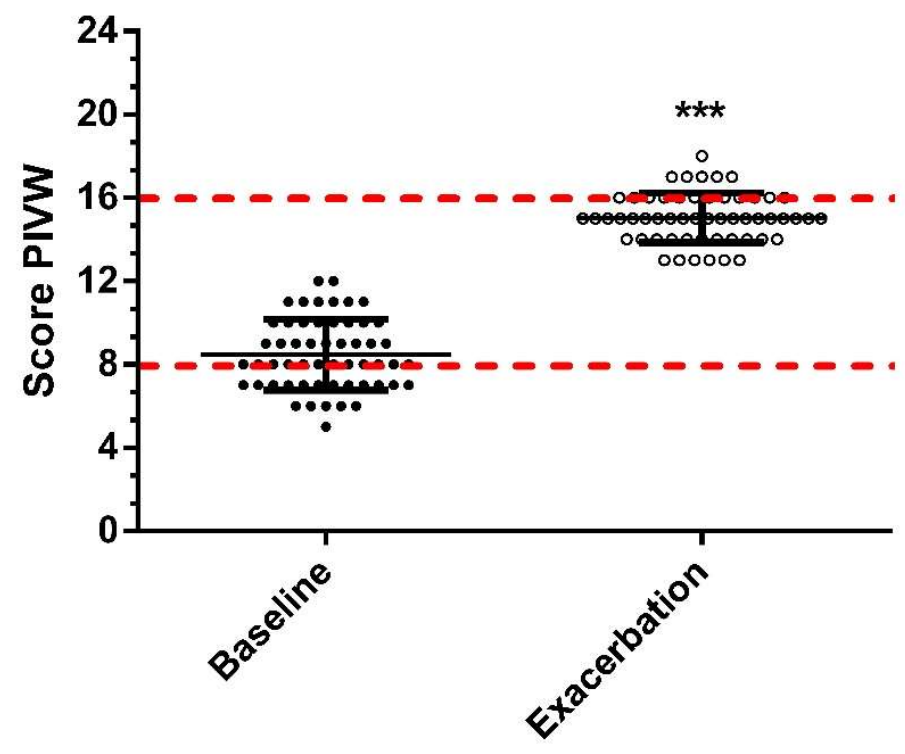

Figure 2. Total score Physiotherapeutic Index of the Impairment of Ventilatory Work. in baseline and exacerbation. The red line represents the change in the categorization of the ventilatory pattern. ${ }^{* * *}$ $\mathrm{P}<0.001$.

\section{DISCUSSION}

The PIVW was sensitive to the change in ventilatory compromise during exacerbations, detecting a significant modification of the total score in patients ( $p<0.001$ ). In addition, it allowed to detect the behavior of this specific group of patients; the number of patients categorized as severe $(33.33 \%)$ increased and patients with a mild commitment $(0 \%)$ disappeared, while the group with a moderate commitment remained stable. This confirms the ability of the scale to detect exacerbation as a global effect and visualize where the main magnitude of change occurs.

Regarding this, Cancino et al., (2004) studied the behavior of PIVW in secondary night care, for this they carried out 291 evaluations in 64 patients, here they observed that $81 \%$ of these were between 9 and 16 points and $4 \%$ on the 16 points, concluding that $85 \%$ of the patients presented a moderate to severe ventilatory compromise [7]. The results of the present investigation also show that most of the patients concentrated on a moderate compromise $(66.67 \%)$.

If respiratory physiotherapy is located within the global historical framework, which has more than a century of evolution, it will be accepted that, despite this, a poor unification of criteria is maintained when evaluating and intervening [12]. Smith et al., (2010) reaffirm this idea, stating that the evaluation and clinical decision making depends on the physiotherapist's experience [13]. However, the high inter-evaluator reliability of the PIVW reported by Cabib et al., (2004) [4], transforms this index as a possible option to implement for the evaluation of respiratory disorders.

The PIVW deepens the analysis of a patient, due to its division into charges, translators and assists (Table 3). This would allow to discriminate the type of behavior that a particular patient assumes, since it is not only important to know the globality of the ventilatory commitment, but also the specific profile that it adopts. In this sense, Quintero et al., (2014) set out to describe and disseminate the usefulness of PIVW in the intervention of the hospitalized patient due to the lack of specialization in this branch, suggesting that it is vital to disseminate tools that allow complementing 
187

188

189

190

191

192

193

194

195

196

197

198

199

200

201

202

203

204

205

206

207

208

209

210

211

212

213

214

215

216

217

218

219

220

221

222

223

224

225

226

a correct examination, evaluation, diagnosis, prognosis and treatment of patients requiring respiratory physiotherapy [14].

When analyzing the variables that make up the PIVW, it can be seen that the Loads (AR and PM) increased significantly, from their baseline to the time of exacerbation. Specifically, the RA showed a significant rise to scores two and three in the exacerbation, which it is consistent with the PM where there was a significant rise to score 2 (94.44\%). This coincides with that reported by Pinochet et al., (2004) who evaluated hospitalized patients, finding for all the variables of the PIVW a value that fluctuated between the two and three points [4]. However, this sample was made up of hospitalized patients with and without the need for non-invasive mechanical ventilation. One of the possible causes of this increase in loads is that indicated by Ha and Rogers (2016), where excess mucin production and increased exocytosis in the secretory cells [15] of the airways reduces bronchial lumen and therefore would increase the AR [16]. Parallel to this, Gagnon et al., (2016) state that the loss of elastic retraction in the lungs increases the average value of functional residual capacity (FRC) or lung volume at the end of expiration (EELV) after quiet exhalation [17] fact that would explain the decrease in MP.

In the Translations, the most important increasements were reported in the variables UAM and APA, where in exacerbation the score two showed $98.15 \%$ and the score $383.33 \%$ of the patients, respectively. Here, the increasement in EELV reported previously, would shorten the expiratory time, in theory, the system compensates for its ventilatory needs by increasing the RR. However, when the increasement in RR does not replace the gas exchange deficit, the UAM increases the expiratory flow and normalizes the tidal volume $[17,18]$.

Finally, in the Supports, the additional contribution of $\mathrm{O} 2$ showed no significant changes. On the other hand, the Cough committed to exacerbation, raising its score to 1 and 2 points $(87.04 \%$ and $12.96 \%$, respectively). These results indicate that parallel to the increasement in the severity of PIVW, there is a compromise of this mechanism (table 3). This situation is relevant, because cough is considered one of the most important symptoms in patients with COPD [19]. Despite this, its causes and diagnosis are difficult to determine, since both analog visual scales and questionnaires specially designed for research are subjective [20]. Its main objective is the permeabilization of the airway, therefore, its worsening in addition to contributing a score on its own in the PIVW, would also add to the total value of this due to its impact on the APA.

The PIVW is a clinical tool, so its use requires training to characterize the subjective variables. Thus, the recommendation for an interested operator is to establish content validation and interevaluation reliability [13]. Although there are enough scores to work with respiratory disorders, they have been created for medical or pharmacological monitoring purposes [21]. Regarding this, the contribution of this index is that it addresses variables directly linked to the physiotherapeutic actions, therefore, in its purpose each of the variables is susceptible to a specific physiotherapeutic intervention, which allows the optimization of decision making. In this context, it requires a specific therapeutic approach for each pathological condition and for each patient. In conclusion, the PIVW serves to determine ventilatory problems in respiratory patients, characterizing the specific changes of loads, translators or supports.

Author Contributions: Conceptualization: R.M.C., G.M.V., R.P.U., M.E.C; methodology: R.M.C, P.A.L., M.E.C, M.D.S; software: G.M.V., P.M.G., J.V.V., P.A.L.; validation: R.M.C., G.M.V., R.P.U., M.E.C.; formal analysis: R.M.C, M.D.S., P.A.L., P.M.G.; investigation: R.M.C, M.D.S., M.E.C, P.A.L; data curation: G.M.V., R.M.C; writing-original draft preparation: R.M.C, P.M.G., P.A.L., M.E.C; supervision: R.M.C; project administration: R.M.C.

Funding: This research received no external funding.

Acknowledgments: We thank all participants included in the cohort study for their kind participation in this research.

Conflicts of Interest: The authors declare no conflict of interest. 


\section{REFERENCES}

1.- López, A.; Pinochet, P.; Crisóstomo, S.; Véliz, C.; Escobar, M. Patokinesiología: un modelo para el estudio de la disfunción del movimiento. UCMaule Revista Académica. 2008, 34, 57-71.

2.- Escobar, M.; Perret, A.; Guerrero, A.; Gomolán, P., Pinochet, R. Uso del índice kinésico de la carga de trabajo ventilatorio en el Área de Gestión Clínica del niño del Hospital Padre Hurtado. Revista del Colegio de Kinesiólogos. 2000, 60, 78-84.

3.- Pinochet, R.; Henríquez, L.; Cabib, C.; Cancino, C.; Villamizar, G.; Escobar, M. Rendimiento del índice kinésico de la carga de trabajo ventilatorio en condiciones clínicas de distinta gravedad. Rev Chil Med Int. 2004, 19, 179-86.

4.- Cabib, C.; Villamizar, G.; Cancino, C.; Henríquez, L.; Foster, I.; Deik, M.; Pizarro, A.; Pinochet, R. Confiabilidad interevaluadores del índice kinésico de la carga de trabajo ventilatorio modificado para pacientes ventilados con presión de soporte. Rev Chil Med Int. 2004, 19, 179-86.

5.- Escobar, M.; Gomolan, P.; Guerrero, A.; González, C.; Vásquez. G.; Vidal, R.; Donoso, A. Kinesic index score evaluation of the ventilatory work load (KIVWL) in children with an acuet respiratory pathology. 14th International WCPT Congress world physical therapy. Barcelona 7-12 junio 2003. Spain.

6.- González, C.; Valenzuela, J.; Guerrero, A.; Escobar, M. Correlación entre score de Tal e Índice Kinésico de Carga de Trabajo Ventilatorio en lactantes con infección respiratoria aguda. Revista del Colegio de Kinesiólogos. 2004, 74, 13-7.

7.- Cancino, C.; Hernández, L.; Cabib, C.; Pinochet, R.; Foster, I. Descripción del comportamiento del índice kinésico de carga de trabajo ventilatorio (IKCTV) en turno nocturno en el Hospital Padre Hurtado. Rev Chil Med Int. 2004, 19, 179-86.

8.- GOLD. [Global Initiative for Chronic Obstructive Lung Disease. Global strategy for the diagnosis, management, and prevention of chronic obstructive pulmonary disease Report]. file://C:/Users/Alonso\%20Mu\%C3\%B1oz\%20Cofr\%C3\%A9/Downloads/wms-GOLD-2017FINAL.pdf (accessed on 12 de october de 2018).

9.- Couillard, A.; Tremey, E.; Prefaut, C.; Varray, A.; Heraud, N. The self-perception of dyspnoea threshold during the 6-min walk test: a good alternative to estimate the ventilatory threshold in chronic obstructive pulmonary disease. Int J Rehabil Res. 2016, 39, 320-25.

10.- Programas de Salud Respiratoria. Ministerio de Salud, Gobierno de Chile. [Programa de control de las enfermedades respiratorias del adulto en Chile: Manual Operativo]. (accessed on 12 october,

2018).

http://web.minsal.cl/sites/default/files/files/Manual operativo Programas de Salud Respirato ria.pdf.

11.- McGarvey, L. Cough • 6: Which investigations are most useful in the diagnosis of chronic cough? Thorax. 2006, 59, 342-46.

12.- Postiaux, G. Chest physical therapy of the distal lung. Mechanical basis of a new paradigm. Rev Mal Respir. 2014, 31, 552-67.

13.- Smith, M.; Higgs, J.; Ellis, E. Effect of experience on clinical decision making by cardiorespiratory physiotherapists in acute care settings. Physiother Theory Pract. 2010, 26, 89-99.

14.- Quintero, J.; Naranjo, F.; Reyes, M.; Reyes, A. La Atención de Fisioterapia Respiratoria del Paciente Hospitalizado. $5^{\circ}$ Congreso Nacional de Tecnología Aplicada a Ciencias de la Salud, Puebla 5-7 junio, 2016. México.

15.- Ha, E.V.; Rogers, D.F. Novel Therapies to Inhibit Mucus Synthesis and Secretion in Airway Hypersecretory Diseases. Pharmacology. 2016, 97, 84-100.

16.- Yan, X.; Song, Y.; Shen, C.; Xu, W.; Chen, L.; Zhang, J.; Liu, H.; Huang, M.; Lai, G.; Qian, G.; Wang, J.; Ye, X.; Zheng, J.; Bai, Ce. Mucoactive and antioxidant medicines for COPD: consensus of a group of Chinese pulmonary physicians. Int J Chron Obstruct Pulmon Dis. 2017, 22, 803-12.

17.- Gagnon, P.; Guenette, J.A.; Langer, D.; Laviolette, L.; Mainguy, V.; Maltais, F.; Ribeiro, F.; Saey, D. Pathogenesis of hyperinflation in chronic obstructive pulmonary disease. Int J Chron Obstruct Pulmon Dis. 2014, 9, 187-201. 
288
18.- Vanfleteren, L.E.G.W.; Spruit, M.A.; Wouters, E.F.M.; Franssen, F.M.E. Management of chronic obstructive pulmonary disease beyond the lungs. Lancet Respir Med. 2016, 4, 911-24.

19.- Ovsyannikov, E.; Avdeev, S.; Budnevsky, A.; Shkatova, Y. Influence of Anxiety/Depression on the Subjective Evaluation of Cough in Patients with Chronic Obstructive Pulmonary Disease and Obesity. Medicina. 2019, 55, 134.

20.- DeVries, R.; Kriebel, D.; Sama, S. Validation of the breathlessness, cough and sputum scale to predict COPD exacerbation. NPJ Prim Care Respir Med. 2016, 26, 16083.

21.- Roberts, N.; Ward, M.; Patel, I.; York, J.; Partridge, M. Reflections on integrated care from those working in and leading integrated respiratory teams. London J Prim Care. 2018, 10, 24-30. 